\title{
Deadly combination: the mixture of drugs and alcohol
}

\section{Short Communication}

Each year, thousands of deaths from drug overdose could have been prevented through proper warnings but millions of people don't take warning labels seriously despite all the news regarding drug-related deaths due to overdose. In fact, many feel reluctant to care about the possible side effects of combining different types of substances. Some even get addicted with multiple substances simultaneously called "polysubstance dependence."

Everyone knows the danger of taking too much drug but people should also be aware that even a small amount of combined substance can be fatal. Generally, any drug can increase the potent level of another drug if two drugs are combined together. In this category, the combination of drug and alcohol is the most common and dangerous of all. The most dangerous combination of drugs and alcohol that had caused rise in rehab admission in the United States includes the following:

\section{Alcohol and opiates}

Opiate is a class of drug that is often combined with alcohol. Opiates include heroin, codeine, morphine, Vicodin and OxyContin. Usually, people take opiate painkillers to manage their pain injuries but some users find greater relief when it is combined with alcohol. According to National Criminal Justice Reference Service, coupling these two drugs can increase the sedative effects of alcohol which heightens the chances of overdose, unconsciousness, and respiratory failure.

A 2010 report from SAMHSA found that around 19,000 of individuals admitted in alcohol rehab have also abused opiates, while 28,000 people who entered opiate rehab have also abused alcohol. These figures indicate a significant portion of Americans struggling with alcohol and opiate abuse.

\section{Alcohol and benzodiazepine}

Benzodiazepines are often prescribed to treat anxiety, muscle spasms, and seizures. According to Drug Enforcement Agency Xanax, Valium, Klonopin, and Ativan are some of the most commonly prescribed benzos. Many are abusing these substances separately, but some are combining the two to increase the drug effect. This dangerous combination is likely to cause dizziness, confusion, aggression, and irritability while abuse in great quantities can lead to memory impairment, unconsciousness, massive organ failure, coma and death.

A 2011 study conducted by SAMSHA found that $95 \%$ of patients admitted in rehab facility for benzodiazepine abuse have also reported for another drug abuse. Alcohol is the other drug accounted for nearly $25 \%$ of those patients.

\section{Alcohol and stimulants}

Adderall, Ritalin, cocaine and methamphetamine are all stimulant drugs that can mask the effects of alcohol, causing users to drink more
Volume 2 Issue I - 2016

\author{
Kelly Greene \\ Substance Addiction Blogger, University of Southern California, \\ USA \\ Correspondence: Kelly Greene, Substance Addiction Blogger, \\ University of Southern California, USA, \\ Email kellygreeneII4@gmail.com \\ Received: September 30, 2015 | Published: January 09, 2016
}

than intended. This can lead users to binge drinking and can even lead to alcohol poisoning and possible death. The other side effects of the combined substance include high blood pressure, increase body temperature, raise of heart rate and seizures.

The non-medical use of Adderall, ADHD medication, is on the rise according to Substance Abuse Treatment, Prevention, and Policy. The study shows that about $7 \%$ of adults aged $18-49$ are abusing the drug, while half of this population is also abusing alcohol while using Adderall. Full-time college students are among the largest group that abuses ADHD medication. The National Survey on Drug Use and Health states that about $90 \%$ of students abusing Adderall are also binge drinkers.

\section{Alcohol and antidepressants}

All antidepressants have warning not to mix them with any other medications, especially the mixture of antidepressants and alcohol because the interaction of alcohol and antidepressant like Elavil and Prozac can put individuals at high risk. Alcohol can make user feel more depressed and anxious which counteracts the benefits of antidepressant medications, making the symptoms more difficult to treat. Other effects of the drug mixture include dangerously high blood pressure, impaired thinking, increased depression, suicidal thoughts, and death.

Mixing alcohol with any drug always presents some danger. The degree of risks will always depend on the mixed substance, the amount used, and the patient's health condition. Given the complexity of interaction between mixed substances, it will always be difficult to identify the level of alcohol consumption that can be considered safe. Many could have been saved from drug overdose if people would take warnings seriously, similar of how they treat cancer.

\section{Biography}

Kelly Greene is a drug and alcohol addiction blogger at Recovery Experts. She has spent several years, providing readers insights about the most up-to-date development in the field of substance addiction and recovery. She wished to develop an extensive understanding of the broad coverage of substance abuse so that everyone can work together to solve the problem of addiction. You may connect with Kelly via Email or LinkedIn. 


\section{Acknowledgements}

None.

\section{Conflict of interest}

The author declares no conflict of interest. 